\title{
CORRELAÇÃO ESPACIAL ENTRE OS USOS E COBERTURA DA TERRA E A TEMPERATURA DE SUPERFÍCIE NAS ÁREAS URBANAS DE FRANCISCO BELTRÃO E PATO BRANCO/ PR
}

\author{
ANALYSIS OF SPATIAL CORRELATION BETWEEN VEGETATION \\ AND SURFACE TEMPERATURE IN THE URBAN AREAS OF \\ FRANCISCO BELTRÃO AND PATO BRANCO/ PR
}

\author{
ANÁLISIS DE LA CORRELACIÓN ESPACIAL ENTRE LA \\ VEGETACIÓN Y LA TEMPERATURA DE SUPERFICIE EN LAS ÁREAS \\ URBANAS DE FRANCISCO BELTRÃO Y PATO BRANCO/ PR
}
Elvis Rabuske Hendges - Universidade Estadual do Oeste do Paraná - Paraná - Cascavel - Brasil elvis_hendges@hotmail.com
Juliano Andres - Universidade Estadual do Oeste do Paraná - Paraná - Cascavel - Brasil juliano.andres@unioeste.br
Fabiano André Marion - Universidade Estadual do Oeste do Paraná - Paraná - Cascavel - Brasil fabiano.marion@unioeste.br

\begin{abstract}
Resumo
A vegetação é um fator determinante das condições climáticas de determinado local. Assim, o objetivo desta pesquisa visa verificar a correlação espacial existente entre a vegetação e a temperatura de superfície encontrada nas áreas urbanas de Francisco Beltrão e de Pato Branco. 0 satélite LANDSAT 8, através de seus sensores OLI e TIRS, possibilita realizar mapeamentos de uso da terra e da temperatura de superfície em mesma escala. A área urbana de Francisco Beltrão apresentou um total de 4.551 ha, sendo 1.041 ha de solo urbano, 2.584 ha de vegetação florestal e 926 ha de vegetação rasteira. Já Pato Branco possui uma área urbana total de 6.204 ha, com 3.167 ha de solo urbano, 1.466 ha de vegetação florestal e 1.571 ha de vegetação rasteira. Quanto à temperatura de superfície registrada, as duas áreas urbanas estudadas tiveram uma variação térmica entre os $19^{\circ} \mathrm{C}$ e os $35^{\circ} \mathrm{C}$, sendo as áreas florestais com variação de $19^{\circ} \mathrm{C}$ a $29^{\circ} \mathrm{C}$ e a classe de solo urbano em sua maioria entre $24^{\circ} \mathrm{C}$ a $35^{\circ} \mathrm{C}$. A correlação de Pearson para ambas as variáveis em sua distribuição espacial apresentou um valor aproximado de 0,75 , considerada uma correlação forte.

Palavras-chave: Sensoriamento remoto, urbanização, uso da terra.
\end{abstract}

\begin{abstract}
Vegetation is an important determining factor in the climatic conditions of a given location. Thus, the objective of this research is to verify the existing spatial correlation between the vegetation and the surface temperature found in the urban areas of Francisco Beltrão and Pato Branco (Brazil). The LANDSAT 8 satellite, through its $\mathrm{OLI}$ and TIRS sensors, enables the mapping of land use and surface temperature on the same scale. The urban area of Francisco Beltrão presented a total of 4,551 ha, 1,041 ha of urban land, 2,584 ha of forest vegetation and 926 ha of undergrowth. Pato Branco has a total urban area of 6,204 ha, with 3,167 ha of urban land, 1,466 ha of forest vegetation and 1,571 ha of undergrowth. As for the surface temperature recorded, the two urban areas studied had a thermal variation between $19^{\circ} \mathrm{C}$ and $35^{\circ} \mathrm{C}$, with forest areas varying from $19^{\circ} \mathrm{C}$ to $29^{\circ}$
\end{abstract}


$\mathrm{C}$ and the majority of urban land between $24^{\circ} \mathrm{C}$ to $35^{\circ} \mathrm{C}$. The Pearson correlation for both variables in their spatial distribution presented an approximate value of 0.75 , considered a strong correlation.

Keywords: Remote sensing, urbanization, land use.

\section{Resumen}

La vegetación es un importante determinante en las condiciones climáticas de un determinado lugar. El objetivo de la presente investigación es comprobar la correlación espacial existente entre la vegetación y la temperatura de superficie encontrada en las áreas urbanas de Francisco Beltrão y de Pato Branco (Brasil). El satélite LANDSAT 8, mediante sus sensores OLI y TIRS, permite realizar mapeos del uso de la tierra y de la temperatura de superficie a la misma escala. El área urbana de Francisco Beltrão presentó un total de 4.551 ha, siendo 1.041 ha de suelo urbano, 2.584 ha de vegetación forestal y 926 ha de vegetación rastrera. El área urbana de Pato Branco posee un área total de 6.204 ha, con 3.167 ha de suelo urbano, 1.466 ha de vegetación florestal y 1.571 ha de vegetación rastrera. Con respecto a la temperatura de superficie registrada, las dos áreas urbanas estudiadas tuvieron una variación térmica entre los $19^{\circ} \mathrm{C}$ y los $35^{\circ} \mathrm{C}$ y las áreas forestales una variación entre $19{ }^{\circ} \mathrm{C}$ y $29^{\circ} \mathrm{C}$ y la clase de suelo urbano, en su mayoría, entre los $24^{\circ} \mathrm{C}$ y los $35^{\circ} \mathrm{C}$. La correlación de Pearson para ambas variables en su distribución espacial presentó un valor aproximado de 0,75, considerada una correlación fuerte.

Palabras clave: Sensación remota, teledetección, uso de la tierra.

Introdução

O clima é regido por um conjunto integrado de fenômenos (fatores e elementos) que se fundem no tempo e no espaço, revelando unidades passíveis de serem medidas (Ribeiro, 1993, p. 288). Uma das relações mais estreitas entre os fatores climáticos e as condições atmosféricas de tempo situa-se no equilíbrio existente entre a radiação solar e a vegetação, vínculo este evidenciado pelas coincidentes zonas climáticas e biomas terrestres.

Em observações locais, a topografia, a superfície do solo, a vegetação e as ações antrópicas passam a ser mais relevantes (Carvalho, 2001, p. 28). Oliveira (1988, p. 06), ao analisar o conceito de clima como "série dos estados da atmosfera, em sua sucessão habitual em um determinado lugar”, diz que este lhe conserva um caráter sintético, porém enfatiza o aspecto local e dinâmico de observação.

No aspecto local, o clima urbano é resultado de ações antrópicas e geoambientais no sítio urbano e áreas circunvizinhas, variando as dimensões do espaço geográfico e do dinamismo das atividades sobre ele impostas (Oliveira, 1988, p. 13), podendo ser analisado na escala de mesoclima (Ribeiro, 1993, p. 292). Os principais fatores condicionantes do clima urbano são: a radiação solar, as características da forma urbana (elementos da morfologia da cidade como rugosidade, porosidade e propriedades termodinâmicas) e a existência/distribuição das áreas verdes (Oliveira, 1988, p. 24). 
A relação entre as áreas verdes e a temperatura do ar se dá no controle da radiação solar (pois esta serve para reduzir a incidência dos raios sobre o solo) e da umidade do ar através da evapotranspiração (Oliveira, 2011, p. 130). Para Santos et al. (2012, p. 547), a cobertura vegetal, em especial a arbórea (através de sua folhagem mais densa), absorve a maior parte da radiação eletromagnética vinda do sol (consumida no processo de fotossíntese), impede que esta chegue a superfície e através de sua reflexão aqueça a camada de ar próxima. Este fato estabelece uma relação direta entre os dados da temperatura de superfície (Ts) e a temperatura atmosférica (Coelho; Ramos; Bergamaschi, 2015, p. 1323).

Em grandes metrópoles as áreas verdes como parques, praças e jardins, favorecem condições de conforto térmico aos habitantes. Mesmo em cidades de médio e pequeno porte pode-se perceber a influência da vegetação arbórea na temperatura, principalmente em meio a áreas construídas (Oliveira; Alves, 2013, p. 64). As variações térmicas decorrentes da urbanização ocorrem basicamente por causa das diferenças de irradiação de calor entre as áreas impermeabilizadas e as áreas verdes, e por causa da concentração de poluentes (que bloqueiam a irradiação de calor da superfície) (Lombardo, 1985, p. 24-25).

Nesse sentido, a presente pesquisa visa, através do processamento de dados oriundos do Sensoriamento Remoto, realizar um estudo de correlação espacial entre as variáveis climáticas vegetação (mapa de uso da terra) e temperatura (Ts) nas áreas urbanas de Francisco Beltrão e Pato Branco. Estima-se que mesmo as referidas cidades não sendo metrópoles, ambas possam apresentar Ts mais elevadas em suas áreas centrais em detrimento de um uso e cobertura da terra florestal em áreas de seu entorno.

Os municípios de Francisco Beltrão e Pato Branco estão situados na mesorregião sudoeste paranaense, conforme classificação do IBGE (Figura 01). Como aspecto climático, segundo o ITCG (2008), as áreas urbanas pesquisadas apresentam um clima de transição, com predomínio de um clima temperado (Cfb). A condição climática da região apresenta temperatura média anual de $21,4^{\circ} \mathrm{C}$, sendo os meses de dezembro, janeiro e fevereiro os mais quentes e os meses de junho, julho e agosto os meses mais frios do ano. As chuvas apresentam índices anuais entre $1.600 \mathrm{e}$ $1.900 \mathrm{~mm}$ precipitados e umidade relativa do ar de $85 \%$. A temperatura e a umidade são fatores determinantes na espacialização dos remanescentes nativos da vegetação característicos dos domínios fitogeográficos de Floresta Ombrófila Mista (mata de Araucária nas regiões mais elevadas) e Floresta Estacional Semidecidual, compostas por espécies subtropicais localizadas em áreas de menor altitude (Ipardes, 2004). 


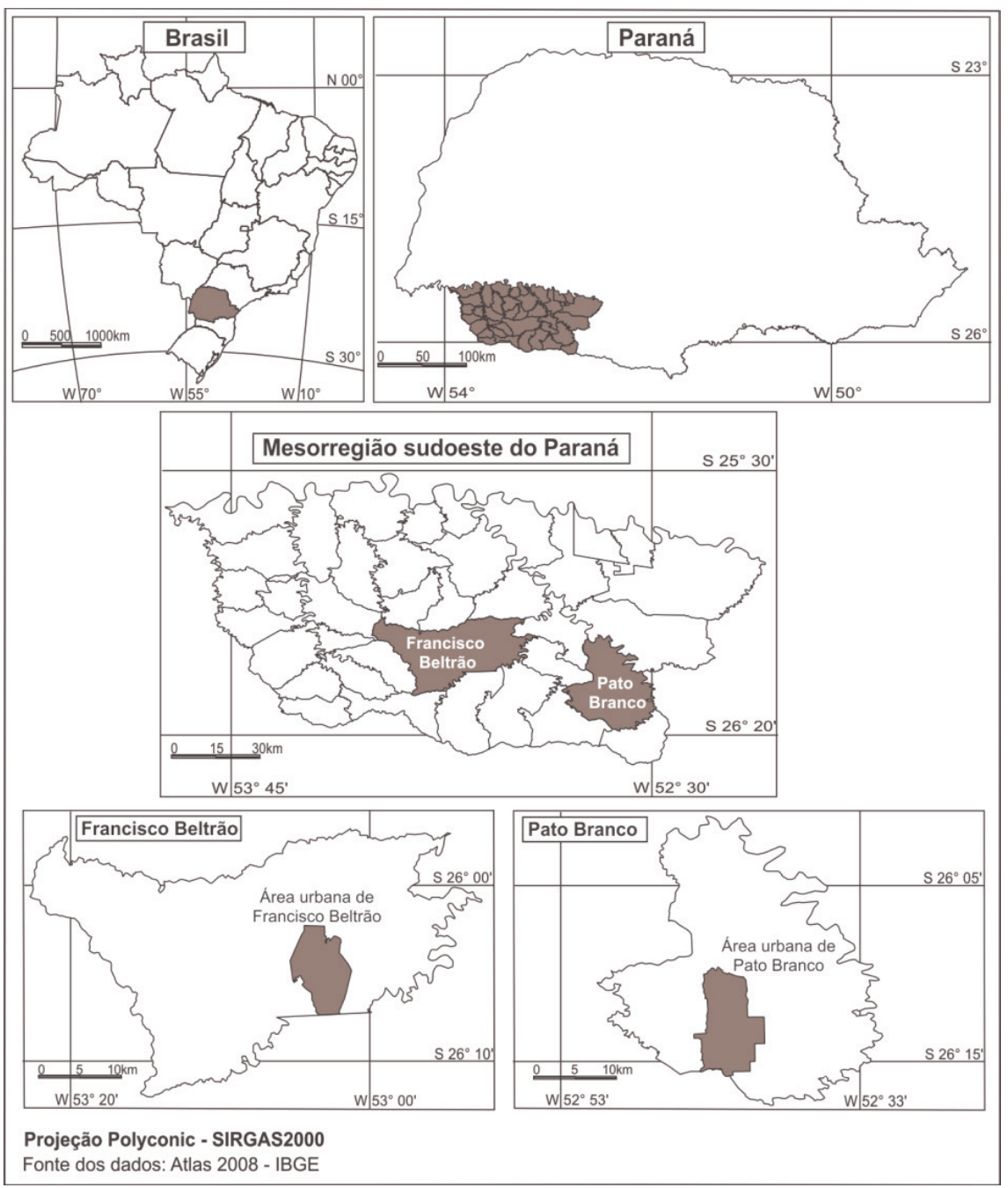

Figura 01 - Mapa de localização das áreas de estudo

Fonte: Elaborada pelos autores, 2017.

Estudos socioeconômicos realizados pelo IBGE (2010) classificam Francisco Beltrão e Pato Branco como as maiores centralidades do espaço na mesorregião, sendo que Pato Branco se especializou mais na área da educação, ciência e tecnologia, enquanto que Francisco Beltrão está mais 
voltada para o comércio e os serviços. A Tabela 01 apresenta os dados censitários da área de estudo.

Por serem centros regionais, nos últimos anos (IBGE, 2010), a taxa de urbanização de Francisco Beltrão (85\%) e Pato Branco (94\%) vem apresentando valores acima da média nacional (84\%). Este fator faz com que as respectivas áreas cresçam de forma desordenada. Para Leme (2015, p. 133), o intenso crescimento populacional urbano registrado na última década gerou uma grande demanda por moradia, impondo dois tipos de expansão: a horizontal, marcada pela abertura de loteamentos; e a vertical, identificada pela construção de edifícios, geralmente com mais de três pavimentos.

Tabela 1 - Dados censitários dos municípios de Francisco Beltrão e Pato Branco

\begin{tabular}{ccc}
\hline Índice & Francisco Beltrão & Pato Branco \\
\hline Área do município (km2) & 735,111 & 539,087 \\
População estimada 2016 & 87.491 & 79.869 \\
População 2010 & 78.943 & 72.370 \\
Densidade demográfica 2010 (hab/km²) & 107,39 & 134,25 \\
População urbana & $67.449(85 \%)$ & $68.091(94 \%)$ \\
Domicílios recenseados & 27.909 & 26.213 \\
\hline
\end{tabular}

Fonte: Elaborada pelos autores (IBGE, 2010).

Material e método

Como fontes de dados referentes às informações de uso e cobertura da terra, adotou-se as imagens do Satélite LANDSAT 8, que possui dois sensores de observação terrestre. O primeiro, denominado Operational Land Imager (OLI), voltado para o mapeamento de padrões de uso e cobertura da terra, possui 9 bandas espectrais, com uma resolução espacial de $30 \mathrm{~m}$. O segundo, direcionado ao comprimento de onda do infravermelho termal, conhecido como Thermal Infrared Sensor (TIRS), com uma resolução espacial inicial de $100 \mathrm{~m}$, reamostradas e disponibilizadas com $30 \mathrm{~m}$ de resolução espacial para que coincidam com as bandas multiespectrais do sensor OLI (Ariza, 2013, p. 9). 
A imagem do satélite LANDSAT 8, datada de 24 de novembro de 2016, foi adquirida junto ao sítio da internet do United States Geological Survey (USGS), (<https://landsat.usgs.gov/landsat-data-access $>$ ). As imagens foram importadas para um Banco de Dados Geográfico delimitado por coordenadas representativas da área de estudo. As bandas espectrais 1, 2, 3, 4, 5, 6 e 7 foram utilizadas para realização da classificação automatizada dos pixels em temas de uso da terra.

A fim de diminuir a confusão da matriz de classificação das imagens, foram definidas três classes de uso da terra: Vegetação Florestal (cobertura arbórea), Vegetação Rasteira (lavouras e campo) e Solo Urbano (áreas urbanizadas e solo exposto). A reflectância da vegetação é determinada por vários fatores como geometria das folhas, a morfologia, a fisiologia e a química das plantas (Ponzoni; Shimabukuro; Kuplich, 2012, p. 22). Estes fatores, ligados ao ângulo de incidência da luz solar, permitem que técnicas de processamento digital de imagens diferenciem espécies vegetais em extratos (Moreira, 2011). Já o comportamento espectral das rochas e de elementos urbanos como concreto, asfalto, telhados, é bastante semelhante, o que dificulta a diferenciação dos alvos e acarreta em uma variação maior da resposta espectral destes elementos (Jensen, 2009, p. 459).

A classificação não supervisionada foi realizada utilizando o classificador K-médias. Em estudo recente de Abrão et al. (2015, p. 5445), ao avaliar o desempenho do algoritmo K-médias na classificação de imagens do sensor OLI, descreveu que este apresentou resultados satisfatórios para os mapeamentos de uso da terra.

O nível de confiança da imagem classificada foi obtido através de uma matriz de confusão a fim de verificar os erros oriundos do processo de agrupamento de pixel a determinada classe. A referida matriz utilizou uma grade de pontos amostral aleatoriamente distribuída e significativa à área classificada. Segundo Luchesa (2011, p. 15), a Equação 01 formula a determinação do tamanho da amostra (n) com base na estimativa da média populacional (tamanho da área). 


$$
n=\frac{N \cdot \sigma^{2} \cdot\left(Z_{\alpha / 2}\right)^{2}}{(N-1) \cdot(E)^{2}+\sigma^{2} \cdot\left(z_{\alpha / 2}\right)^{2}}(01)
$$

Em que:

$n=$ Número de amostras.

$N=$ Tamanho da população.

$\square=$ Desvio Padrão populacional da variável estudada.

$Z_{a_{12}}=$ Valor crítico que corresponde ao grau de confiança desejado.

$E$ = Margem de erro ou erro máximo de estimativa.

Com a distribuição espacial dos pontos amostrais foram elaboradas as matrizes de confusão geradas a partir da revalidação da classificação. Os pixels classificados foram comparados com imagens de altíssima resolução espacial $(0,5 \mathrm{~m})$ do satélite Pléiades 1A (desenvolvido pela agência espacial francesa, CNES), disponibilizadas pelo aplicativo Google Earth. A abordagem de validação de classificação foi elaborada por Moreira (2011, p. 370), que usa como base as imagens de alta resolução espacial capturadas do Google Earth e técnica de interpretação visual descrita por Novo (2010, p. 328).

A avaliação da acurácia foi baseada em Congalton (1991, p. 36), através do cálculo do coeficiente Kappa, que leva em consideração toda matriz de confusão, inclusive os elementos de fora da diagonal principal. Os níveis de desempenho segundo o índice Kappa são: $<0$ = péssimo; 0 $0,2=$ ruim; $0,2-0,4=$ razoável; $0,4-0,6=$ bom; $0,6-0,8=$ muito bom; e $0,8-1,0=$ excelente. Para calcular o coeficiente Kappa, será utilizada a Equação 02.

$$
K=\frac{n \sum_{i-1}^{c} x_{i i}-\sum_{i-1}^{c} x_{i+} x_{+i}}{n^{2}-\sum_{i-1}^{c} x_{i+} x_{+i}}(02)
$$

Em que:

$K=$ Coeficiente Kappa.

$n=$ Total de amostras.

$\sum_{i-1}^{c} x_{i i} \sum_{i-1}^{c} x_{i i}=$ Soma da diagonal principal da matriz de erro.

$\sum_{i-1}^{c} x_{i+} x_{+i} \sum_{i-1}^{c} x_{i+} x_{+i}=$ Somatório do produto das linhas e colunas da matriz de erro. 
Para o mapeamento da Ts, Schott et al. (2014, p. A2) ressaltam a banda 10 do LANDSAT 8, a qual pode ser utilizada após a calibração através de modelos de correção atmosférica e de parâmetros para recuperação da Ts, porém ainda se reconhece um erro de polarização residual inferior a 2 graus para os alvos (Schott et al., 2014, p. A10).

Para o modelo de correção atmosférica em imagens do sensor termal TIRS, primeiramente foi necessário realizar o cálculo dos valores de transmissividade atmosférica, da radiância emitida e da radiância recebida pela superfície através do site da NASA (<http://atmcorr.gsfc.nasa.gov./>); para tal procedimento informou-se dados como: a temperatura do ar $(29,4$ $\left.{ }^{\circ} \mathrm{C}\right)$, a pressão atmosférica (950 hPa) e a umidade (45\%) local na hora do registro da imagem. Desta forma, com os dados da transmissividade atmosférica $(0,86 \mathrm{~K})$, da radiância emitida $\left(1,10 \mathrm{~W} / \mathrm{m}^{2} . \mathrm{sr} . \mu \mathrm{m}\right)$ e recebida $\left(1,88 \mathrm{~W} / \mathrm{m}^{2} . \mathrm{sr} . \mu \mathrm{m}\right)$ pela superfície, através da Equação 01 (Barsi; Barker; Schott, 2003, p. 3014) foi possível efetuar o cálculo da radiância (Lt):

$$
L t=\frac{L_{T O A^{-}}-L_{u}-(1-\varepsilon) \cdot L_{d}}{\tau \cdot \varepsilon}(03)
$$

Em que:

$L t=$ Radiância de um alvo negro de temperatura cinética $\left(\mathrm{W} / \mathrm{m}^{2} . \mathrm{sr} . \mu \mathrm{m}\right)$.

$L_{T O A}=$ Radiância espectral $\left(\mathrm{W} / \mathrm{m}^{2}\right.$. sr. $\left.\mu \mathrm{m}\right)$.

$\tau=$ Transmissividade atmosférica.

$\varepsilon=$ Emissividade da superfície ${ }^{1}$.

$L u=$ Radiância emitida pela superfície $\left(\mathrm{W} / \mathrm{m}^{2} . \mathrm{sr} . \mu \mathrm{m}\right)$.

$L d=$ Radiância recebida pela superfície $\left(\mathrm{W} / \mathrm{m}^{2} . \mathrm{sr} . \mu \mathrm{m}\right)$.

Após a correção atmosférica, realizou-se o cálculo da Ts a partir da conversão dos níveis de cinza da banda 10 em radiância espectral através da Equação 04 (USGS, 2017). Com o cálculo realizado, foram ainda convertidos os valores de Ts resultantes para graus Celsius $\left({ }^{\circ} \mathrm{C}\right) \operatorname{com}$ a subtração do valor da temperatura do ponto de congelamento da água ao nível do mar, que equivale a $273,15^{\circ}$ Kelvin. 


$$
L_{\lambda}=M_{L} \cdot Q_{\text {cal }}+A_{L}(04)
$$

Em que:

$L \lambda=$ Radiância espectral $\left(\mathrm{W} / \mathrm{m}^{2} . \mathrm{sr} . \mu \mathrm{m}\right)$.

$M_{L}=$ Fator multiplicativo de redimensionamento da banda $\left(3,3420 . \mathrm{e}^{-4}\right)$.

$Q_{\text {cal }}=$ Valor quantizado e calibrado do pixel em nível de cinza (DN).

$A_{L}=$ Fator aditivo de redimensionamento da banda $(0,1)$.

Os cálculos definidos pelas expressões matemáticas anteriormente mencionadas, bem como os processos de cruzamento das informações espaciais entre os mapas de uso da terra e da Ts registrados, foram realizados através da álgebra de mapas, implementada com a programação de Linguagem Espacial para Geoprocessamento Algébrico (LEGAL), no aplicativo SPRING.

A fim de verificar estatisticamente se o fator vegetação, espacializado pelo mapa de uso da terra, influencia na distribuição espacial do elemento climático Ts, foram cruzadas informações nas coordenadas preestabelecidas pelos pontos amostrais. Com os dados oriundos deste cruzamento será calculada a correlação de Pearson. O coeficiente de correlação linear de Pearson, segundo Turkman e Silva (2000, p. 39), estabelece um parâmetro de medida correlativa que determina um nível de intensidade das relações entre as variáveis. Os resultados neste coeficiente apresentam valores num intervalo de -1 a 1, sendo: 0,01 a 0,39 a correlação fraca; 0,40 a 0,69 a correlação média; e 0,70 a 0,99 a correlação forte.

\section{Resultados}

Ao verificar os limites urbanos definidos pelos mapas de zoneamento urbano e oficializados nos Planos Diretores dos municípios, leis: Lei Municipal n 3.380/2007 de Francisco Beltrão e Lei Complementar $n^{\circ}$ 48/2012 de Pato Branco, por meio da digitalização do limite das áreas urbanas, essas apresentaram respectivamente 4.551,05 ha e 6.203,87 ha. Este valor afere os dados do censo do IBGE (2010) que atesta que o município de Pato Branco apresenta um grau de urbanização superior ao de Francisco Beltrão, mesmo este apresentando uma menor população de munícipes. Também dos mapas de zoneamento foram digitalizados os principais cursos de drenagem e os eixos rodoviários. 
Com a classificação das bandas, a classe solo urbano, que engloba padrões espectrais semelhantes (uso urbano e solo exposto), quantificou para a área urbana de Francisco Beltrão um total de 2.584,1 ha; a classe vegetação florestal (composta por uma cobertura arbórea florestal) quantificou uma área de 1.040,85 ha; e a classe vegetação rasteira (composta por áreas de cultivo agrícola e de campo/pastagens) totalizou 926,1 ha. Para as mesmas classes de uso, Pato Branco somou: $3.166,11$ ha para solo urbano; 1.467,36 ha para vegetação florestal; e 1.570,4 ha para vegetação rasteira. Cabe destacar que ambos os limites urbanos englobam áreas destinadas à expansão urbana, com presença de vegetação florestal e rasteira (diferentes estágios de cultivo agrícola e de campo). Existem ainda áreas de solo exposto, caracterizadas por loteamentos em fase inicial de implantação.

Após a classificação, foi realizado o cálculo que definiu os 34 pontos amostrais para Francisco Beltrão e 29 pontos para Pato Branco, utilizando-se $95 \%$ de valor para o grau de confiança e 5\% como margem de erro. Assim, a grade aleatória estimou uma distancia média entre pontos amostrais de 1,8 km para longitude e 1,2 km para latitude em Pato Branco, resultando em 30 pontos no total. Para Francisco Beltrão, foram estipuladas as distâncias de 1,6 km para longitude e $750 \mathrm{~km}$ para latitude. Por conta de sua forma geométrica bastante peculiar, a grade de pontos amostrais gerada foi de 36 .

Quando comparadas as imagens classificadas (mapas de uso da terra) com as imagens disponibilizadas pelo Google Earth datadas de 01/07/2016 (Francisco Beltrão) e 23/05/2016 (Pato Branco), nos pontos amostrais predefinidos, foram geradas as matrizes de confusão especificadas no Quadro 01.

\begin{tabular}{|cccc|}
\hline Área urbana de Francisco Beltrão & \multicolumn{3}{c|}{} \\
\hline & Vegetação florestal & Vegetação rasteira & Solo urbano \\
Cobertura florestal & 6 & 0 & 2 \\
Vegetação & 0 & 8 & 2 \\
Solo urbano & 1 & 2 & 15 \\
\hline Área urbana de Pato Branco & & & Solo urbano \\
\hline & Cobertura florestal & Vegetação rasteira & 0 \\
Cobertura florestal & 7 & 2 & 3 \\
Vegetação & 1 & 7 & 10 \\
Solo urbano & 0 & 0 & 0 \\
\hline
\end{tabular}

Quadro 1 - Matrizes de confusão da validação da classificação dos mapas de uso da terra 
A partir da matriz de confusão foi calculado o coeficiente Kappa para analisar o grau de confiabilidade das classificações de ambas as áreas. Este cálculo resultou em valores de 0,68 para Francisco Beltrão e 0,70 para Pato Branco, ambos os valores enquadrados em um nível de classificação substancial $(0,61<\mathrm{K}>$ 0,8) (Landis; Koch, 1977, p. 165).

A imagem referente à banda 10 do sensor TIRS, após ser submetida à correção atmosférica e ser transformada para valores de Ts em graus Celsius, apresentou uma variação entre 19 e $35^{\circ} \mathrm{C}$. As condições de temperatura atmosférica, às 10h30min da manhã, no dia 24 de novembro de 2016, registradas pelas estações meteorológicas do SIMEPAR (Sistema Meteorológico Paranaense) de Francisco Beltrão (-26 05’ 01,96” lat; - 53 ${ }^{\circ} 03$ ’51,05” long) e Pato Branco (-26 $07^{\circ} 24,28^{\prime \prime}$ lat; - $52^{\circ} 39^{\prime} 07,05^{\circ}$ long) foram de $25,24^{\circ} \mathrm{C}$ e $26,22^{\circ} \mathrm{C}$ respectivamente.

Ao realizar a parametrização da temperatura média do ar registrada com o pixel de Ts registrada pelo sensor na localização das respectivas estações $\left(26,1^{\circ} \mathrm{C}\right.$ e $\left.27,3^{\circ} \mathrm{C}\right)$ foi observado um acréscimo de aproximadamente $1{ }^{\circ} \mathrm{C}$. Desta forma, Weng, Lu e Schubring (2004, p. 481) e Coelho, Ramos e Bergamaschi (2015, p. 1325), em seus estudos ressaltam que a temperatura média de superfície apresenta, normalmente, valores mais elevados em relação à temperatura média do ar, porém essa diferença não infere nos resultados, uma vez que a temperatura quantificada pelo satélite é a temperatura radiante da superfície.

Ao correlacionar os dados dos mapas de uso da terra e da Ts, foi estipulado que as áreas de floresta seriam locais onde potencialmente a temperatura dos alvos seria menor quando comparadas às áreas de vegetação rasteira e de solo urbano respectivamente. Assim, o valor de correlação de Pearson apresentou valores positivos de 0,7544 para Francisco Beltrão e de 0,7501 para Pato Branco, valores que se encaixam numa escala de correlação forte entre as variáveis. $\mathrm{O}$ Quadro 02 apresenta o diagrama de dispersão dos valores correlacionados.

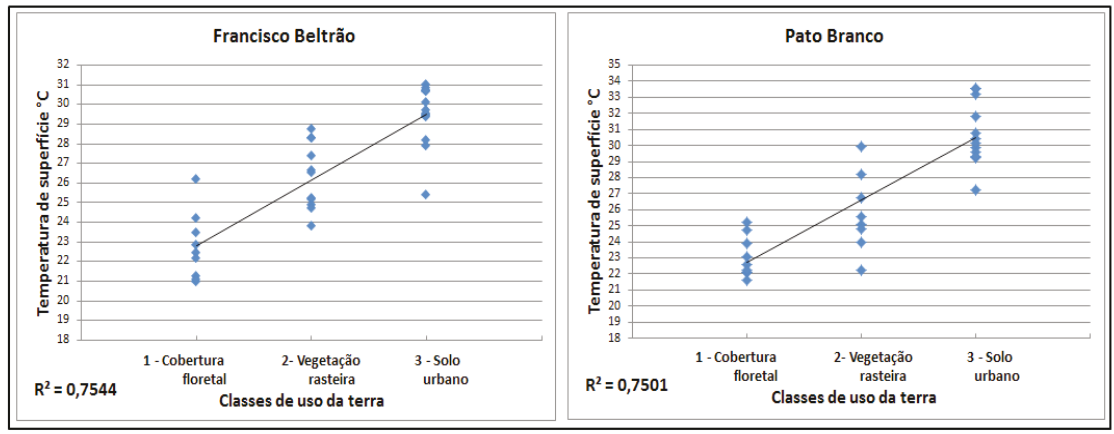

Quadro 2 - Diagrama de dispersão e correlação entre a distribuição espacial dos valores de Ts e as classes de uso da terra 
Ao agrupar as Ts em intervalos de tempo, a relação calculada e descrita como positiva e de forte influência entre as classes de uso da terra e as Ts registradas podem ser percebidas visualmente ao comparar os mapas correlacionados (Figura 02).

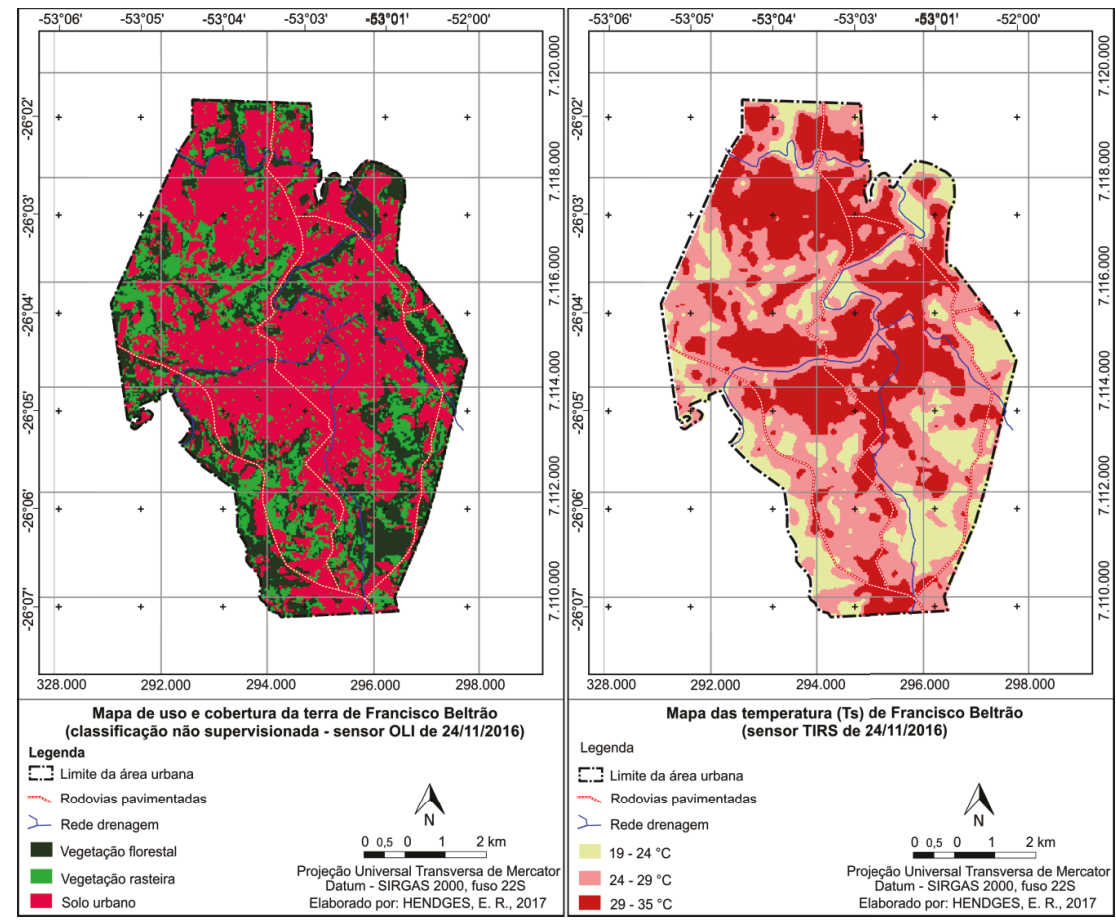

Figura 2 - Mapas de Uso da terra e das Ts da área urbana de Francisco Beltrão

Fonte: Elaborada pelos autores, 2017.

Para a área urbana de Francisco Beltrão nota-se que nos locais onde a cobertura florestal possui uma maior dimensão em área, as Ts são classificadas no menor intervalo estabelecido (19-24 $\left.{ }^{\circ} \mathrm{C}\right)$. Já na área mais central de Francisco Beltrão, onde a concentração de edificações, populacional e de veículos é maior, as Ts apresentaram valores no intervalo de $29-35{ }^{\circ} \mathrm{C}$. Lombardo (2009, p. 115) afirma que as variações térmicas observadas entre as zonas urbanas e rurais podem chegar até $12{ }^{\circ} \mathrm{C}$, tendo como causas principais a substituição da vegetação natural pelo excesso de concreto/asfalto e o adensamento das edificações/ações antrópicas. 
Cabe aqui também ressaltar que a vegetação mesmo em áreas menores, como nas estreitas faixas marginais dos rios, também auxilia como fator moderador da temperatura. Este fato é percebido no caso de Francisco Beltrão, onde a presença de matas galeria, ao longo da hidrografia dos principais rios apresenta temperaturas numa classe intermediária de $24-29^{\circ} \mathrm{C}$.

Ao comparar os mapas de uso e das Ts da área urbana de Pato Branco, a correlação existente entre a distribuição espacial das variáveis mapeadas também é perceptível. Nota-se que locais onde existe a presença de vegetação, as temperaturas tendem a ser menores inclusive em áreas centrais da cidade (Figura 03). A correlação encontrada concorda com Weng, Lu e Schubring (2004, p. 480), que afirmam que a vegetação em suas diferentes formas influencia decisivamente no controle da qualidade ambiental. Assim, em espaços urbanos a presença da cobertura vegetal tem um efeito amenizador do aquecimento térmico gerado pelas edificações e superfícies pavimentadas.

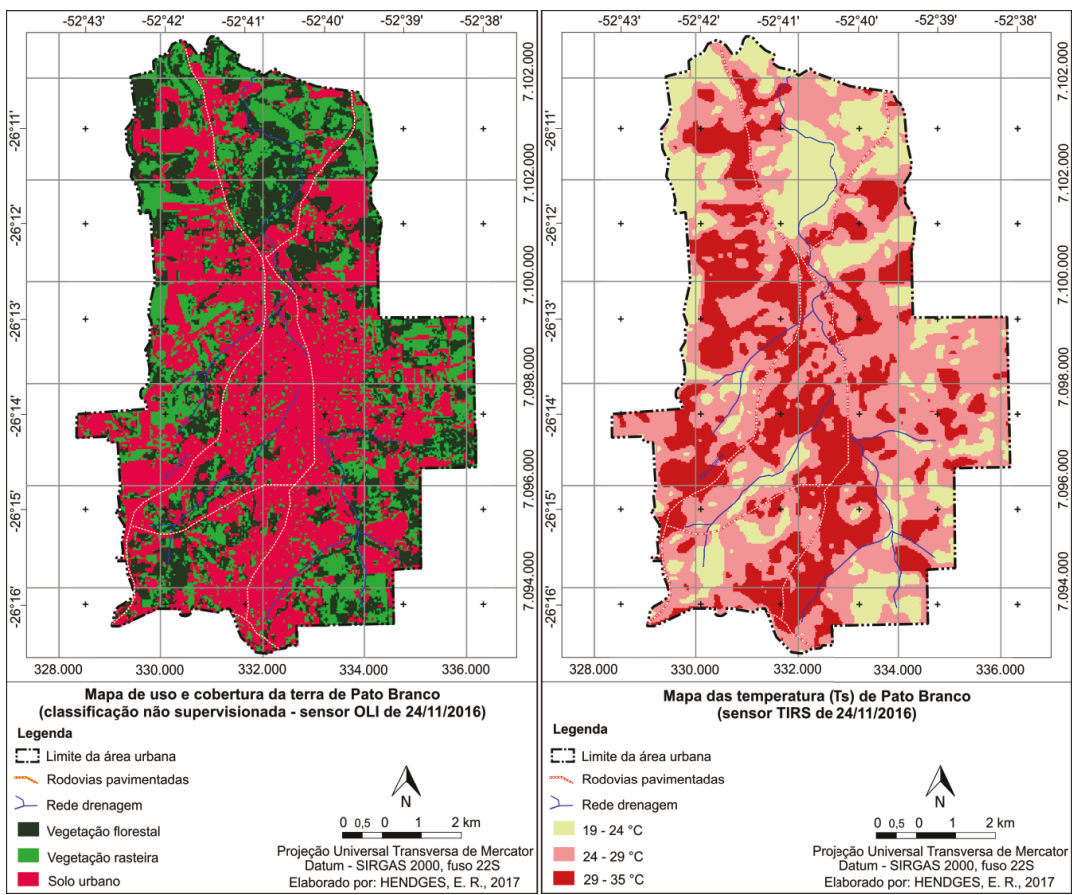

Figura 3 - Mapas de Uso da terra e das Ts da área urbana de Pato Branco 
O Quadro 03 representa a importância da vegetação, em especial a arbórea, como agente moderador da temperatura; se faz representar na distribuição espacial que relaciona a distribuição do total das áreas de cada classe de uso, pela sua respectiva temperatura para cada grau Celsius identificado. Nesse sentido, a vegetação florestal é a classe de uso com mais áreas com menores temperaturas, sendo em sua grande maioria, áreas com temperaturas inferiores a $26{ }^{\circ} \mathrm{C}$. Pode-se perceber também que a vegetação florestal não apresenta áreas com mais de $29^{\circ} \mathrm{C}$. A vegetação rasteira, classe de uso que apresenta um maior equilíbrio de suas áreas conforme a temperatura, também decresce em área após os 26 ${ }^{\circ} \mathrm{C}$, apresentando a máxima temperatura de $31{ }^{\circ} \mathrm{C}$.

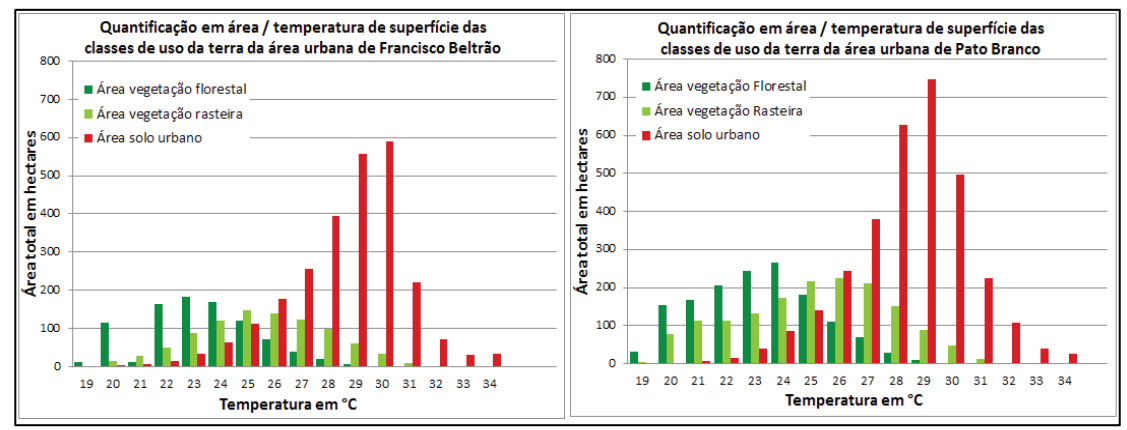

Quadro 03 - Distribuição em área das temperaturas conforme classe de uso da terra Fonte: Elaborado pelos autores, 2017.

Ao contrário da vegetação florestal, o solo urbano começa a destacar suas áreas a partir de $24{ }^{\circ} \mathrm{C}$ (mesmo apresentado poucas áreas com temperaturas variando entre 21 e $23^{\circ} \mathrm{C}$ ). A maioria das áreas dessa classe de uso apresenta temperaturas que oscilam entre $28^{\circ} \mathrm{C}, 29^{\circ} \mathrm{C}$ e 30 ${ }^{\circ} \mathrm{C}$. Já acima dessa temperatura, o número de áreas começa a decrescer significativamente.

Nesse sentido, Martinelli e Santos Jr. (2015, p. 119) ressaltam que num ambiente urbano a árvore tem incorporado estreita relação com a arquitetura das cidades, e a arborização urbana contribui para obtenção de um ambiente urbano térmico agradável, tendo influência decisiva na qualidade de vida nas cidades (Gomes; Amorim, 2003, p. 104). 


\section{Conclusão}

Como proposto inicialmente pela hipótese, a presente pesquisa pode confirmar que a vegetação é um fator determinante no elemento climático temperatura, essa afirmação pode ser confirmada pelo elevado grau de correlação encontrado na distribuição espacial de ambos os alvos mapeados. É preciso referir, porém, que as condições meteorológicas de tempo, e posterior do clima, são variáveis dependentes de inúmeros outros fatores condicionantes.

O atual estágio de urbanização apresentado pelos centros regionais da mesorregião sudoeste do Paraná (Francisco Beltrão e Pato Branco) já apresentam influência de elementos urbanos na sensação de conforto térmico, uma vez que as suas áreas urbanas atingiram temperaturas de superfície superiores as encontradas em usos com predomínio de cobertura vegetal (em especial áreas com florestas). Este fator é explicado por Labaki et al. (2011, p. 31-32) quando afirmam que em espaços urbanos a presença de vegetação, em especial a arbórea, desempenha papel importante na sensação térmica, principalmente em dias ensolarados, quando a parte verde das plantas absorve grande parte da radiação solar.

Quanto à metodologia adotada: para elaboração do mapa de uso e cobertura da terra, o algoritmo classificador, quando avaliado diante das classes definidas, mostrou-se confiável para a área de estudo, com um satisfatório agrupamento dos pixels conforme seu nível de brilho diante do número de classes pré-definidas; os processos de correção atmosférica e de conversão de radiância em TS também mostraram-se confiáveis ao comparar os dados da Ts registrada pelo sensor TIRS e as temperaturas ambiente registradas pelas estações meteorológicas de Francisco Beltrão e Pato Branco.

Por fim, recomenda-se, ao levar em consideração os conhecidos problemas gerados pelas ilhas de calor registrados em centros urbanos maiores, e pela ocorrência de um mesoclima (com temperaturas superiores às médias regionais) nas cidades de Francisco Beltrão e Pato Branco, que as políticas públicas possam promover um maior incentivo à implantação de parques florestais (bosques e reservas naturais) e demais espaços verdes em consonância ao desenvolvimento urbano. 


\section{Notas}

1 Como parâmetro de entrada, correspondente a emissividade, optou-se em utilizar o valor de $0.92 \mathrm{~K}$, o qual corresponde ao valor médio das superfícies urbanas (Nichol, 1994, p. 1228).

\section{Referências}

aBRÃO, C. M. R. et al. Avaliação de classificadores supervisionados e não supervisionados para mapeamento de uso e cobertura da terra a partir de dados Landsat-8/OLI. In: XVII SIMPÓSIO BRASILEIRO DE SENSORIAMENTO REMOTO - SBSR, 2015, João Pessoa. Anais... João Pessoa: INPE, 2015. p. 5439-5446. Disponível em: <http://www.infoteca.inf.br/sbsr/smarty/templates/arquivos_template/upload arquivos/acervo/docs/p1085.pdf>. Acesso em: 12 jun. 2017.

ANDRES, J. Qualidade de vida na cidade de Francisco Beltrão (PR) por meio de Sistemas de Informações Geográficas: aproximações entre objetividade e subjetividade. 2015. 285 f. Tese (Doutorado em Geografia) - Pós-Graduação em Geografia, Universidade Federal do Paraná, Curitiba, ago. 2015.

ARIZA, A. Descripción y corrección de productos landsat 8 LDCM (Landsat Data Continuity Mission) Versión 1.0. Bogotá, Colombia: Instituto Geográfico Agustín Codazzi, 2013.

BARSI, J. A.; BARKER, J. L; SCHOTT, J. R. An atmospheric correction parameter calculator for a single thermal band earth-sensing instrument. In: GEOSCIENCE AND REMOTE SENSING SYMPOSIUM, 2003, Cidade. Anais... Toulouse: IGARSS03, 2003. p. 3014-3016. Disponível em: <https://atmcorr.gsfc.nasa.gov/ Barsi_IGARSS03.PDF > Acesso em: 14 jun. 2017.

CARVALHO, M. M. de. Clima urbano e vegetação: estudo analítico e prospectivo do parque das Dunas em Natal. 2001. 283 f. Dissertação (Mestrado em Arquitetura e Urbanismo) - Programa de Pós-Graduação Stricto Sensu em Arquitetura e Urbanismo, Universidade Federal do Rio Grande do Norte, Natal, abr. 2001.

COELHO, A. L. N.; RAMOS, A. L. D.; BERGAMASCHI, R. B. Aplicação dos Produtos Landsat-8/TIRS/OLI e Aster/GDEM na Avaliação do Comportamento Termal de Superfície, Usos e Topografia. In: XVII SIMPÓSIO BRASILEIRO DE SENSORIAMENTO REMOTO - SBSR, 2015, João Pessoa. Anais... João Pessoa: INPE, 2015. p. 1323-1330. Disponível em: < http://www.dsr.inpe.br/sbsr2015/ files/p0241.pdf> Acesso em: 12 jun. 2017.

CONGALTON, R. G. A review of assessing the accuracy of classifications of remotely sensed data. Remote Sensing of Environment, Califórnia, v. 49, n. 12, p. 1671-1678, 1991.

GOMES, M. A. S.; AMORIM, M. C. de C. T. Arborização e conforto térmico no espaço urbano: estudo de caso nas praças públicas de Presidente Prudente (SP). Caminhos de Geografia, Uberlândia, v. 7, p. 94-106, 2003. 
IBGE. Instituto Brasileiro de Geografia e Estatística. Base de Informações do Censo Demográfico 2010: resultados do universo por setor censitário documentação do arquivo. Rio de Janeiro: IBGE, 2011. p. 125

IPARDES. Instituto Paranaense de Desenvolvimento Econômico e Social. Leituras regionais: Mesorregião Geográfica Sudoeste Paranaense. Curitiba: BRDE, 2004. $140 \mathrm{p}$.

IBGE. Instituto Brasileiro de Geografia e Estatística. Banco de Metadados. Rio de Janeiro: IBGE, 2010. Disponível em: < https://censo2010.ibge.gov.br/resultados. html>. Acesso em: 28 jun. 2017.

ITCG - Instituto de Terras, Cartografia e Geologia do Paraná. Clima - Estado do Paraná. Curitiba, 2008.

JENSEN, J. R. Sensoriamento Remoto do Ambiente: Uma Perspectiva em Recursos Terrestres. Tradução José Carlos Neves Epiphanio et al. (Coord.). São José dos Campos, SP: Parêntese, 2009. p. 598.

LABAKI, L. C. et al. Vegetação e conforto térmico em espaços urbanos abertos. Revista Fórum Patrimônio - Ambiente Construído e Patrimônio Sustentável, Belo Horizonte, v. 4, n. 1, p. 23-42, 2011.

LANDIS, R. J.; KOCH, G. G. The measurement of observer agreement for categorical data. Biometrics, v. 33, n. 1, p. 159-174, 1977.

LEME, R. C. Expansão urbana e verticalização: o mercado imobiliário de Francisco Beltrão/PR (1998 a 2012). 2015. 377 f..Tese (Doutorado em Geografia) - Programa de Pós-Graduação em Geografia, Universidade Federal de Santa Catarina, Florianópolis, abr. 2015.

LOMBARDO, M. A. A Ilha de Calor nas Metrópoles. São Paulo: Hucitec, 1985. p. 244.

. Análise das mudanças climáticas nas metrópoles: o exemplo de São Paulo e Lisboa. In: ORTIGOZA, S. A. G.; CORTEZ, A. T. C.(Org.). Da produção ao consumo: impactos socioambientais no espaço urbano. São Paulo: UNESP, 2009. p. 111-146.

LUCHESA, C. J. Cálculo do tamanho da amostra nas pesquisas em administração. Curitiba: Edição do Autor, 2011. p. 27.

MARTINELLI, A.; SANTOS JR., A. R. Arborização Urbana do município de Itapira - SP: perspectivas para educação ambiental e sua influência no conforto térmico. Revista Eletrônica em Gestão, Educação e Tecnologia Ambiental, Santa Maria, v. 19, p. 1018-1031, 2015.

MOREIRA, M. A. Fundamentos do sensoriamento remoto e metodologias de aplicação. Viçosa, MG: UFV, 2011. p. 422.

NICHOL, J. E. A GIS-Based Approach to Microclimate Monitoring in Singapore's High-Rise Housing Estates. Photogrammetric Engineering \& Remote Sensing, v. 60, n. 10, p. 1225-1232, 1994.

NOVO, E. M. L. de M. Sensoriamento remoto: princípios e aplicações. São Paulo: Edgard Blucher Ltda, 2010. p. 387. 
OliveIRA, P. M. P. de. Cidade apropriada ao clima: a forma urbana como instrumento de controle do clima urbano. Brasília: UNB, 1988. p. 134.

OLIVEIRA, A. S. Influência da vegetação arbórea no microclima e uso de praças públicas. 2011. 162 f. Tese (Doutorado em Física Ambiental) - Programa de PósGraduação em Física Ambiental, Universidade Federal de Mato Grosso, Cuiabá, jul. 2011.

OLIVEIRA, M. M. de; ALVES, W. S. A influência da vegetação no clima urbano de cidades pequenas: um estudo sobre as praças públicas de Iporá-GO. Revista Territorial, Goiás, v. 2, p. 61-77, 2013.

PONZONI, F. J.; SHIMABUKURO, Y. E.; KUPLICH, T. M. Sensoriamento Remoto no Estudo da Vegetação. São Paulo: Oficina de Textos, 2012. p. 160.

RIBEIRO, A. G. As Escalas do clima. Boletim de Geografia Teorética, Rio Claro, v. 23, p. 288-294, 1993.

SANTOS, J. S. dos et al. Campo térmico urbano e sua relação com o uso e cobertura do solo em cidade tropical úmida. Revista Brasileira de Geografia Física, Recife, v. 03, p. 540-557, 2012.

SCHOTT, J. R. et al. Chasing the TIRS ghosts: calibrating the Landsat 8 thermal bands. Earth Observing Systems XIX, Califórnia, v. 9218, p. A1-A20, 2014.

TURKMAN, M. A. A.; SILVA, G. L. Modelos lineares generalizados: da teoria à prática. Lisboa: Universidade de Lisboa, 2000. 151p. Disponível em: < https:// docs.ufpr.br/ taconeli/CE225/tp.pdf > > . Acesso em: 16 jun. 2017.

USGS - United States Geological Survey. Landsat Missions: Using the USGS Landsat8 Product. Section 5 - Conversion of DNs to Physical Units. Disponível em: <http://landsat.usgs.gov/Landsat8_Using_Product.php>. Acesso em: 20 maio 2017.

WENG, Q.; LU, D.; SHUBRING, J. Estimation of land surface temperature vegetation abundance relationship for urban heat island studies. Remote Sensing of Environment, n. 89, p. 467-483, 2004.

Elvis Rabuske Hendges - Possui graduação em Geografia pela Universidade Federal de Santa Maria, mestrado em Geomática pela Universidade Federal de Santa Maria e doutorado em Engenharia Florestal pela mesma Universidade. Atualmente é professor adjunto da Universidade Estadual do Oeste do Paraná. ORCID: https://orcid.org/0000-0003-2304-5634.

Juliano Andres - Licenciado em Geografia e mestre em Geomática pela Universidade Federal de Santa Maria. Doutor em Geografia pela Universidade Federal do Paraná. Atualmente é professor adjunto da Universidade Estadual do Oeste do Paraná. ORCID: https://orcid.org/0000-0002-1206-6483. 
Fabiano André Marion - Graduado em Geografia pela Universidade Federal de Santa Maria, mestre em Geomática pela mesma Universidade. Doutorando pelo programa de pós-graduação em Geografia pela Universidade Estadual do Oeste do Paraná. Atualmente é professor Assistente da Universidade Estadual do Oeste do Paraná. ORCID: https://orcid.org/0000-0002-8762-315X

\section{Contribuições dos autores}

Os autores consideram que a participação na construção da presente pesquisa foi conjunta desde o início da formulação do problema, na revisão conceitual, na definição da metodologia, no processamento digital das imagens, no cruzamento das informações, na análise e na interpretação dos dados, bem como na conclusão e na redação final do artigo.

Recebido para publicação em 29 de novembro de 2017 Aceito para publicação em 05 de janeiro de 2018 